\title{
La contratación de temporeros en las campañas de recolección del sector frutícola*
}

\author{
Rafael Allepuz Capdevila ${ }^{1}$; Teresa Torres Solé
}

Recibido: 12 de septiembre de 2016 / Aceptado: 13 de febrero de 2017

Resumen. El artículo realiza un análisis de la normativa laboral que ha regulado la contratación de trabajadores temporeros durante las últimas décadas. Lo novedoso del trabajo resulta de su aplicación al sector frutícola. Los resultados obtenidos mediante el análisis de la normativa, de sus efectos y de entrevistas en profundidad, muestran que las condiciones laborales que ofrecen las campañas de recolección propician las fugas de los temporeros hacia otros sectores, a pesar de la progresiva adaptación de la legislación a las necesidades de las explotaciones frutícolas. Se observa que las diferentes estrategias de reclutamiento de mano de obra temporal han llevado a un proceso de sustitución entre jornaleros nacionales y extranjeros, muy condicionado a la coyuntura económica del momento. Con el cambio de siglo, las preferencias contractuales mostradas inicialmente por los empresarios frutícolas, que se basaban en la gestión colectiva de las contrataciones en origen, viran hacia el reclutamiento de jornaleros a través de la subcontratación y la prestación de trabajadores, como sería el caso de las ETT.

Palabras clave: trabajadores temporeros; reclutamiento; agricultura frutícola; condiciones laborales.

\section{[en] Recruitment of agrarian temporary workforce in the campaigns for the fruit harvesting}

Abstract. The article performs an analysis of how labor legislation has regulated the hiring of temporary workers in recent decades. The novelty of the work is its application to the fruit sector. The results obtained through the analysis of the legislation, its effects and in-depth interviews, show that the working conditions that offer collection campaigns lead to leaks of the seasonal workers to other sectors despite the progressive adaptation of legislation to the needs of fruit farms. It is observed that the different strategies of recruitment of temporary labor have led to a process of substitution between domestic and foreign laborers, very conditional on the economic situation of the time. With the turn of the century, contractual preferences displayed initially by fruit businesspeople, which relied on the co

* Este documento recoge parte del trabajo realizado por los autores en la ejecución del proyecto "Observatorio permanente de la inmigración de las comarcas de Ponent: estudio de los temporeros de las comarcas de la Plana”. Dicho proyecto está financiado por la Diputación Provincial de Lérida y está siendo llevado a cabo por investigadores del Grupo de Investigación Análisis Social y Educativo (GRASE), Grupo de Investigación Consolidado (2014 SGR-307) de la Generalitat de Catalunya.

1 Miembro del Grupo de Investigación Análisis Social y Educativo (GRASE), Grupo de Investigación consolidado (2014 SGR-307) por la Generalitat de Catalunya.

Universidad de Lleida, Departamento de Economía Aplicada

Rafael.allepuz@econap.udl.cat

2 Miembro del Grupo de Investigación Análisis Social y Educativo (GRASE), Grupo de Investigación consolidado (2014 SGR-307) por la Generalitat de Catalunya.

Universidad de Lleida, Departamento de Economía Aplicada

torres@econap.udl.cat 
llective management of procurement at origin, port the recruitment of workers through subcontracting and the provision of workers, as it would be the case of the TEA (Temporary Employment Agencies).

Key words: agrarian temporary workforce; contracting; fruit farming; working conditions

Sumario. 1. Introducción. 2. Decáda de los ochenta: España en Europa. 3. Saneamiento de la economía española y convergencia al euro (1994-1998). 4. Pertenencia a la UEM y elevado crecimiento (19992008). 5. La recesión y su anhelada recuperación (2009-2016). 6. Conclusiones. 7. Bibliografía.

Cómo citar: Alepuz Capdevilla, R.; Torres Solé, T. (2018) "La contratación de temporeros en las campañas de recolección del sector frutícola". Cuadernos de Relaciones Laborales, 36(1), 107-123.

\section{Introducción}

La condición de temporero o jornalero se produce cuando el trabajador al no encontrar trabajo en su tierra se ve obligado a buscar trabajo en temporadas ocasionales allí donde se necesitan braceros para realizar trabajos que no pueden o no desean realizar los autóctonos del lugar (Tabares, 1990). En España, la agricultura frutícola mantiene un elevado volumen de contratación de temporeros para atender actividades como la recolección de fruta que se realiza de forma manual. Al respecto, Huelva, Castellón o Lérida son enclaves importantes de esta agricultura con la contratación de $60.000,24.000$ y 9.000 temporeros respectivamente para la campaña de fresa y otras berries, citrícos y fruta dulce, según datos facilitados por los sindicatos agrarios. El auge de la actividad estacional durante la campaña de recolección supone un revulsivo importante en el mercado laboral de estas zonas. Cabe destacar que la agricultura frutícola se ha consolidado, en los últimos años, como la principal rama del sector agrario, con una clara vocación exportadora ${ }^{3}$.

El objetivo del artículo es realizar un análisis de la normativa laboral que ha regulado la contratación de trabajadores temporeros durante las últimas décadas. Lo novedoso del trabajo es su aplicación al sector frutícola, haciendo hincapié en la incidencia de los distintos procedimientos regulados y su nivel de adecuación a las dificultades y/o preferencias de contratación de mano de obra temporal de los empresarios del sector.

Para ello se ha recurrido al análisis de la normativa que regula los diferentes procedimientos aplicados a lo largo de las últimas décadas y se han realizado entrevistas de profundidad a los agentes agrarios de las provincias de Huelva, Castellón y Lérida, por ser zonas que registran un elevado volumen de contratación de temporeros agrícolas y enclaves importantes de la agricultura frutícola. La recopilación de información inicial se realizó a través de las Dependencias Provinciales de Trabajo e Inmigración de las subdelegaciones del Gobierno de Huelva, Lérida y Castellón. Ello permitió conocer el volumen de jornaleros llegados en los diversos años a estas

España es el sexto país productor de frutas y hortalizas a nivel mundial y el segundo de la Unión Europea, con una producción de unos 25 millones de toneladas de piezas. Esto representa más del 25\% (Ministerio de Agricultura, Alimentación y Medio Ambiente, 2015). 
provincias, duración de los contratos y tipo de oferta por la que fueron contratados (nominativas o genéricas). Posteriormente, se realizaron diversas reuniones de trabajo mediante entrevistas individuales y semidirigidas a los diferentes agentes del sector frutícola que se consideran cualificados por su vinculación al sector y su conocimiento sobre el mismo. Se trata de pequeños empresarios agrícolas, propietarios de una explotación familiar y también de grandes cooperativas o sociedades agrarias de transformación de las zonas frutícolas que registran un elevado número de temporeros agrícolas (Huelva, La Plana de Lérida y Vall d’Uxó). También fueron entrevistados los representantes de los principales sindicatos agrarios de estas provincias, como UP, UGT, CCOO, JARC o COAG, Inspectores de Trabajo y otras instituciones que ofrecen apoyo en las diversas campañas de recolección de fruta en las zonas de estudio (Ayuntamientos, ETT, fuerzas de seguridad, servicios de ocupación, ONGs y otros organismos locales). Por último, el trabajo de campo se centra en las entrevistas a los propios temporeros contratados. El equipo de trabajo de los diferentes proyectos, que se indican posteriormente, participaron en el diseño de la encuesta realizada a los temporeros de las diversas campañas. Las encuestas fueron ensayadas con antelación, pasándose a un grupo reducido de trabajadores y modificadas para introducir en el cuestionario los ajustes necesarios ${ }^{4}$.

Las entrevistas se iniciaron en el año 2007 en el marco del proyecto "Eficacia de la contratación en origen para la inserción laboral de la población extranjera en Cataluña. Aportaciones para un debate", estudio concedido por la Agencia de Gestión de Ayudas Universitarias y de Investigación de la Generalitat de Cataluña. Posteriormente el trabajo de campo se desarrolló durante las campañas de recolección de 2011 a 2014 en el marco del proyecto de $\mathrm{I}+\mathrm{D}+\mathrm{i}$ financiado por el Ministerio de Ciencia e Innovación (Ref. CSO2010-18764, 2011-2014) “Gestión colectiva de contrataciones agrícolas en origen y sus soportes territoriales en España y Marruecos: propuesta de concatenación de campañas e implicaciones en el codesarrollo". Por último, la campaña 2015 se circunscribe en el proyecto "Observatorio permanente de la inmigración de las comarcas de Lérida: Estudio de los temporeros de las comarcas de La Plana" financiado por la Diputación provincial de Lérida, durante el período de ejecución 2015-2016, en todos ellos los autores del presente trabajo han formado parte en el equipo de investigación.

El artículo está estructurado en seis apartados. Tras la introducción, el segundo se centra en la contratación de temporeros durante el periodo correspondiente a la década de los años ochenta. El tercero desarrolla el análisis normativo que se produce en la década de los noventa. Este análisis se amplía, en el cuarto apartado, para el periodo de crecimiento que se produce en la etapa 1999-2008. El quinto se centra en el cambio de procedimiento que se observa en la contratación de temporeros a raíz de la nueva coyuntura económica recesiva. Por último, se exponen las principales conclusiones.

\footnotetext{
Durante las campañas de 2011 y 2012 se entrevistaron a 50 temporeros contratados en origen que trabajaban en la recogida de fruta dulce en la provincia de Lérida. También a 315 temporeros en la provincia de Huelva durante las campañas de la fresa de 2011 y 2012 y un grupo de trabajadores rumanos contratados en el sector cítrico de Castellón. En la campaña de recolección de la fruta de 2015 se realizaron 900 entrevistas personales a los temporeros que estaban trabajando o buscando trabajo en las poblaciones de la Plana de Lérida. Anteriormente, en el año 2007, se realizaron diversas entrevistas de profundidad a diversos trabajadores extranjeros contratados en origen que en aquel momento trabajaban en diversos sectores de la economía catalana.
} 


\section{Década de los ochenta: España en Europa}

La transformación del modelo de explotación familiar agrícola hacia otro modelo de carácter empresarial implicó la contratación de mano de obra asalariada y la dificultad de encontrar trabajadores dispuestos a ejecutar las tareas agrícolas de recolección, principalmente de fruta, en menor medida mecanizadas. Este proceso, como indica Achón (2013), evidencia, por un lado, la mejora de las condiciones de trabajo y vida experimentada por los españoles en los últimos años de la década de los setenta y durante los ochenta, y por otro, un cambio en el modelo de producción y comercialización agraria, pasando de una economía orientada hacia el mercado interno poco competitivo a una economía dirigida a la exportación.

El proceso de apertura económica y comercial, que culminó con la adhesión de España en la Comunidad Europea (1986) y la implantación del Mercado Único Europeo (1993), fueron los factores que determinaron la creacion de una red de producción-comercialización transnacional (europea) de frutas, en la que se impone una mayor racionalización productiva y se aborda una transformación en la organización productiva y del trabajo. De este modo, se observa que los cambios sociales y económicos de los setenta y ochenta introdujeron importantes modificaciones en la composición interna de la población activa de las agriculturas como la hortofrutícola, que llevaron a una reducción del trabajo propio familiar de la explotación y un incremento del trabajo asalariado, conformándose como agriculturas eminentemente salariales (Segura, et al. , 2002).

Majoral y Sánchez (2002) analizan los datos de los censos agrarios de 1989 y 1999 y señalan que, en el periodo intercensal, se ha producido una substitución del trabajo familiar por asalariado, especialmente en la agricultura más dinámica, donde el recurso a la mano de obra temporal suele guardar relación con el carácter estacional de los cultivos, como por ejemplo la fruta, y con el uso de ciertas técnicas y se localiza de manera preferente en la mitad meridional de la península y a lo largo de la costa mediterránea. Con frecuencia se trata de un trabajo estacional relacionado con la agricultura intensiva de regadío. Se confirma de este modo que los cultivos frutícolas de la fachada mediterránea empleaban un importante número de jornaleros.

$\mathrm{Al}$ inico de esta transformación productiva los empresarios agrícolas contrataban básicamente trabajadores escasamente cualificados dispuestos a realizar el trabajo de recolección por uno de los salarios más bajos del mercado, especialmente en épocas de inestabilidad laboral o pérdida de empleo. La contratación de estos temporeros se caracterizaba por la nula formalización de contratos y un alto grado de incumplimiento en los acuerdos (inobservancia de las normas que rigen la jornada laboral, el pago de horas extras o la filiación a la Seguridad Social), lo cual generaba un sistema de trabajo basado en condiciones que vulneraban los derechos de los trabajadores y les situaba en un estado de indefensión.

El estudio de Tabares (1990) afirma que España durante la década de los ochenta era el país europeo con mayor número de temporeros. El citado trabajo cifra en 600.000 las familias españolas que vivían la condición de temporeros al desplazarse por la geografía española para atender las campañas de la hostelería o en la recolección agraria, o bien se desplazaban a Francia y Suiza con contratos temporales para la vendimia, la construcción o la hostelería.

La estacionalidad de estas actividades no impedía detectar una cierta regularidad y continuidad. Los empresarios agrícolas contrataban cada año los mismos tempo- 
reros de una campaña para otra, en ocasiones durante 20 años seguidos (Vilar et al., 1999). De este modo, los trabajadores en condición de parados, que llegaban de otras regiones, garantizaban la mano de obra temporal necesaria para atender la campaña, entre otras las de fresa, cítricos y fruta dulce. La poca cualificación requerida en estas tareas agrarias de temporada, su baja remuneración y la elevada temporalidad provocaba que determinados colectivos en situación de exclusión social, como por ejemplo el gitano, encontraran en estas actividades un nicho laboral y se especializasen en la recogida de productos frutícolas.

En este contexto, la aprobación de sistemas especiales de protección como los Planes de Empleo Rural a partir de 1984, que tenían como eje central un subsidio por desempleo a favor de los trabadores eventuales incluidos en el Régimen Especial Agrario de la Seguridad Social, llevaron al abandono de estos trabajos de temporada cuando el temporero completaba el número de peonadas suficientes para acceder al cobro de dicho subsidio, un total de 60 jornadas. En esta etapa, las explotaciones frutícolas tuvieron dificultades para contratar temporeros con garantías de permanencia a lo largo de toda la campaña, puesto que los salarios y las condiciones laborales que ofrecían no eran atractivos para la mano de obra disponible, a pesar de que la tasa de paro en esos años superaba el 15\% de la población activa.

\section{Saneamiento de la economía española y convergencia al euro (1994-1998)}

El saneamiento de la economía a mediados de la década de los noventa y la creación de empleo llevó al abandono de las actividades frutícolas por parte de los trabajadores nacionales, que se insertaron en otros sectores con mejores condiciones sociolaborales. Este nicho fue cubierto por los inmigrantes que habían llegado a España, a finales de los años ochenta, procedentes del norte de África y la zona subsahariana que se mostraron dispuestos a trabajar en estas actividades de temporada.

La no formalización de las relaciones laborales mediante un contrato laboral, la remuneración de las horas de trabajo por debajo del convenio colectivo y las jornadas laborales excesivas eran características frecuentes de la situación laboral de estos trabajadores, que se desarrollaban en economía sumergida al amparo de una débil actuación del Ministerio de Trabajo en materia de inspección. Estas condiciones caracterizaron a las actividades agrarias como un trabajo de escasa consideración social (Achón, 2011; Gordo, 2011) destinado a los jornaleros extranjeros que accedían a ellos por las dificultades legales para ocupar otros puestos de trabajo.

La mayor disponibilidad de mano de obra extranjera para el sector frutícola se vio favorecida por el proceso extraordinario de regularización aprobado por el Gobierno en 1991, que contemplaba de manera específica a los trabajadores de temporada. Se establecía que los extranjeros que se encontrasen en España con anterioridad al 15 de mayo de 1991 y contasen con oferta firme, compromiso o contrato de trabajo para la realización de trabajos de temporada o campaña podrían ser regularizados mediante la obtención de un permiso de trabajo tipo $\mathrm{A}^{5}$.

Las Instrucciones aprobadas el 8 de junio de 1991 articularon un procedimiento particular para estos casos:

"Quienes cuenten con oferta de empleo para la realización de trabajos de temporada o campaña podrán obtener su regularización temporal por medio de un procedimiento específico". Del total de 109.135 solicitudes que obtuvieron una resolución favorable en este proceso, el 16\% fueron para trabajadores de la agricultura (Aragón, 
Los datos del Ministerio del Interior (1997 y 2000) indican que entre 1995 y 1998 la cifra de extranjeros con permiso de trabajo en la agricultura prácticamente se duplicó, pasando de 19.771 permisos a 37.919. A este proceso de regularización siguieron los aplicados durante los años 1996, 2000, 2001 y 2005 en los cuales las contrataciones en las actividades agrícolas afloraron un importante número de inmigrantes en situación de irregularidad administrativa.

Ante el auge del flujo inmigratorio, el 9 de abril de 1991, se aprobó una Proposión no de Ley relativa a la situación de los extranjeros en España, en la que se adoptaron una serie de medidas para adecuar la legislación a la nueva realidad social. Se aprobó un programa de actuación que instaba al Gobierno a "desarrollar una política activa de inmigración en la que los poderes públicos, con el amplio respaldo de las fuerzas políticas y sociales, tomen la iniciativa en la canalización y organización de los flujos de inmigración legal en función de las necesidades de mano de obra de la economía española y de la capacidad de absorción de nuestra sociedad". En la práctica dio inicio a la política de cupos o contingentes, adoptada a partir de 1993 por el Consejo de Ministros y vigente a día de hoy, aunque con algunos cambios.

Se basa en la fijación anual de unos cupos para trabajadores extranjeros no comunitarios a los que se les permite entrar en España para trabajar, al considerar que la situación nacional de empleo (SNE) no puede cubrir determinadas vacantes. Se trata de una política que pretende la canalización y el control de los flujos migratorios facilitando un número máximo de autorizaciones, que únicamente se utilizan si el mercado de trabajo nacional no es capaz de satisfacer las necesidades empresariales, evitar que se atiendan de forma irregular y combatir la explotación de inmigrantes y la irregularidad en la contratación por las empresas.

El contingente establecía un cupo temporal asignado al sector agrario. Sin embargo, esta fórmula de reclutamiento no era ágil ni flexible para cubrir las actividades agrícolas de temporada como la recolección, con importantes oscilaciones laborales debido a las condiciones climáticas. A lo anterior se añadía que la previsión del cupo se realizaba a un año vista, dado que los Acuerdos del contingente se adoptaban en diciembre y regían para todo el año siguiente. De este modo, se diseñó un programa diferenciado para las actividades de temporada. El Real Decreto 155/1996, de 2 de febrero ${ }^{6}$ recogió los primeros avances en este sentido. Mantenía el permiso de trabajo "Tipo A" pero "para realizar actividades de temporada o trabajos de duración limitada", fijó en mes y medio el plazo general máximo para resolver las solicitudes del mismo, la mitad del plazo general, y asignó una tramitación también preferente para los visados y permisos de trabajo de temporada.

A pesar de estos avances, el procedimiento seguía siendo demasiado rígido para atender las necesidades de mano de obra temporal de las explotaciones frutícolas, entre otras. Ante esta situación, el Ministerio de Trabajo y Asuntos Sociales convocó una reunión, el 17 de diciembre de 1997, a la que asistieron representantes de las organizaciones agrarias y sindicales, así como la Federación Española de Municipios y Provincias (FEMP). Los acuerdos adoptados quedaron recogidos en el Convenio Marco de Colaboración para la Ordenación de las Migraciones Interiores en las Diversas Campañas Agrícolas de Empleo Temporal con el fin de "obtener una ade-

R. y Chozas, J., 1993). Los nacionales marroquíes, fundamentalmente hombres, fueron los principales beneficiarios.

6 BOE de 23 de febrero de 1996. Corrección de errores en BOE de 2 de abril de 1996. 
cuada planificación y ordenación de las campañas de empleo temporal agrícola y la consiguiente mejora de las condiciones sociolaborales de los trabajadores migrantes" (Cláusula 1). Sus destinatarios eran los jornaleros que se encontraban en España, tanto españoles como comunitarios, y el resto de extranjeros legalmente establecidos en el país. Pese a las buenas intenciones del Convenio Marco, éste tuvo poco éxito.

\section{Pertenencia a la UEM y elevado crecimiento (1999-2008)}

Paralelamente al crecimiento de la economía, los empresarios frutícolas vieron como muchos de los inmigrantes contratados como temporeros abandonaban el sector agrario para ocupar los empleos que se generaban en la construcción y servicios, donde las condiciones sociolaborales eran más atractivas y la estabilidad laboral podía ser mayor. Esta situación generaba una amenaza a la continuidad de las actividades de campaña ante la falta de mano de obra para atenderlas. Para ello, las partes firmantes del Convenio Marco de 1997 suscribieron, el 21 de septiembre de 1999, el Protocolo Adicional con el objetivo de establecer una mayor "colaboración en el establecimiento y desarrollo de un procedimiento subsidiario para la contratación de trabajadores extranjeros en sus países de origen, en campañas agrícolas de temporada, una vez agotadas las posibilidades de contratar trabajadores españoles, comunitarios o extranjeros legalmente establecidos en España" (Cláusula Primera).

El Protocolo recogía también la particularidad de que la implantación de este procedimiento se iría desarrollando progresivamente, "comenzando con experiencias pilotos en zonas delimitadas" (Cláusula Cuarta). La primera experiencia tuvo lugar en junio de 1999 en Lérida, donde el sindicato agrario Unió de Pagesos contrató en origen 35 hombres colombianos para la campaña de recogida de fruta. En el año 2000 se llevaron a cabo en las provincias de Almería, Guadalajara, Tenerife y de nuevo en Lérida. En la campaña de la fresa 2000/2001 esta fórmula de contratación se aplicó también en la provincia de Huelva, con la contratación de 738 trabajadores procedentes de Polonia y Marruecos.

Los contenidos del Convenio Marco y del Protocolo Adicional se incorporaron a la nueva Ley de Extranjería que se aprobó en el año 2000, la Ley Orgánica 4/2000, de 11 de enero, sobre derechos y libertades de los extranjeros en España y su integración social . En ella se reconoce a las actividades de temporada o campaña como un régimen especial. Posteriormente, tras las reformas introducidas en la Ley de Extranjería por la Ley Orgánica 8/2000, de 22 de diciembre ${ }^{8}$, la convocatoria del contingente perdió su carácter anual, quedando supeditada a la necesidad de mano de obra. Desde entonces, se exige que los destinatarios de las ofertas no sean residentes en España ni se hallen en el país.

Estos cambios jurídicos exigieron la aprobación de un nuevo Reglamento de Extranjería: el Real Decreto 864/2001, de 20 de julio9. En él se reguló el permiso de trabajo "Tipo T", el de mayor aplicación en la agricultura, el cual autoriza la realización de actividades o servicios de temporada o campaña, se limita a una actividad y ámbito geográfico concreto y su duración coincide con la del contrato de trabajo, no

BOE de 12 de enero de 2000. Corrección de errores en BOE de 24 de enero de 2000.

BOE de 23 de diciembre de 2000. Corrección de errores en BOE de 23 de febrero de 2001.

BOE de 21 de julio de 2001; Corrección de errores en BOE de 6 de octubre de 2001. 
pudiendo exceder de nueve meses, dentro de un período de doce meses consecutivos. En el procedimiento específico para su obtención se ha incorporado igualmente los contenidos previstos en el Convenio Marco y en el Protocolo Adicional.

En el año 2003 se modifica de nuevo la Ley de Extranjería mediante la Ley Orgánica 14/2003, de 20 de noviembre ${ }^{10}$ que introduce diversas novedades en el contingente, entre ellas, que las ofertas de empleo realizadas a través del contingente se orientarán preferentemente hacia los países con los que España ha firmado acuerdos sobre regulación de flujos migratorio. Entre los años 2001 y 2003 tales acuerdos se suscribieron con Bulgaria, Colombia, Ecuador, Marruecos, Polonia, República Dominicana y Rumanía y posteriormente se hizo también con Mauritania y Ucrania. La normativa clasifica a estos países de carácter "preferente", lo cual facilita que la mayor parte de las ofertas laborales se dirigen a ellos ya que los convenios suscritos incluyen el compromiso, para las autoridades de estos países, de organizar el proceso de preselección de los trabajadores, de ahí que los empresarios frutícolas tengan mayores facilidades para llevar a cabo la selección de los temporeros que desean contratar.

Los anteriores cambios jurídicos hicieron necesaria la aprobación de un nuevo Reglamento de Extranjería, mediante el Real Decreto 2393/2004, de 30 de diciem$b r e^{l l}$. Éste mantuvo las actividades de temporada o campaña como un régimen especial, previéndose que el acuerdo del Consejo de Ministros que aprobase el contingente pudiera regular de manera diferenciada, respecto a las ofertas estables, las particularidades en el procedimiento de contratación de trabajadores de temporada. Como novedad el permiso "Tipo T" pasó a denominarse "autorización de residencia temporal y trabajo por cuenta ajena de duración determinada".

Al respecto, el Acuerdo de contingente de 2004 fue el último en especificar el cupo concreto de temporada. A partir de entonces lo único que se recoge es el procedimiento y se aprueban las ofertas en función de la situación nacional de empleo del momento en que se presentan. Para verificar dicha situación en el Real Decreto 2393/2004 se establece que el empleador debe presentar la oferta de trabajo ante el Servicio Público de Empleo, estatal y/o regional, que dispone del plazo de 25 días para gestionarla y cubrirla con candidatos ya incorporados al mercado laboral español. Solo en el supuesto de que no se encuentren personas adecuadas o suficientes para cubrir los puestos, las ofertas podrán cubrirse con trabajadores extranjeros que se encuentren en su país de origen.

Los agricultores onubenses son los que han apostado en mayor medida por este instrumento de reclutamiento laboral, sobre todo para la recolección de las berries. Con un volúmen bastante más reducido, los empresarios de la fruticultura leridana también han encontrado en el contingente una salida a sus necesidades de mano de obra temporal. Sin embargo, para otras actividades agrarias el reclutamiento laboral por esta vía es poco atractivo debido a la excesiva burocracia requerida, los plazos de tramitación que no son acordes con las necesidades ${ }^{12}$, los costes que conllevan y la carencia de apoyo logístico, entre otros motivos.

Con el objetivo de dinamizar el contingente, el 18 de julio de 2006 volvieron a reunirse las partes firmantes del Convenio Marco y de su Protocolo Adicional. Los

BOE de 21 de noviembre de 2003.

BOE núm. 6, de 7 de enero de 2005.

Dado que las ofertas hay que gestionarlas al menos tres meses antes del momento en el que se va a necesitar al trabajador. 
acuerdos adoptados se concretaron en la firma del Convenio para la ordenación, coordinación e integración sociolaboral de los fujos migratorios laborales en campañas agrícolas de temporada. Su filosofía y contenidos son similares a los recogidos en los dos acuerdos anteriores, quedando su objetivo redactado en los siguientes términos: "establecer la colaboración entre las entidades firmantes del mismo con el fin de asegurar una gestión eficaz de los flujos migratorios laborales, interiores y exteriores, en el sector agrario, de manera que se disponga en cada momento y lugar de los trabajadores necesarios, garantizando el cumplimiento de las normas laborales y de inmigración, las condiciones de trabajo y la adecuada integración sociolaboral de los trabajadores" (Cláusula Primera). De nuevo, la agricultura siguió copando la mayoría de las ofertas tramitadas por la vía del contingente.

Las adhesiones de Bulgaria, Polonia y Rumanía a la Unión Europea provocaron que los nacionales de estos Estados se convirtieran en ciudadanos comunitarios de pleno derecho ${ }^{13}$. Por tanto, dejaron de regirse por la Legislación de Extranjería, pasando del denominado "Régimen General" al "Régimen Comunitario", regulado por el Real Decreto 240/2007, de 16 de febrero, sobre entrada, libre circulación y residencia en España de ciudadanos de los Estados miembros de la Unión Europea y de otros Estados parte en el Acuerdo sobre el Espacio Económico Europeo ${ }^{14}$. Para sustituir estas "bajas" y aumentar las alternativas de la inmigración selectiva por países, el Acuerdo que reguló el contingente para el año $2008^{15}$ estableció que las ofertas de empleo se cursarían "preferentemente a los países con los que España tiene suscritos acuerdos sobre regulación y ordenación de flujos migratorios o, subsidiariamente, instrumentos de colaboración en esta materia" (Apartado 4.3).

La Ley Orgánica 2/2009 de 11 de septiembre reformó de nuevo la Ley de Extranjería ${ }^{16}$, desde entonces, el procedimiento para reclutar temporeros extranjeros que no se encuentran en España ha pasado a denominarse "gestión colectiva de las contrataciones en origen" (GECCO). Se mantiene el "régimen especial de trabajadores de temporada", a los que se les reserva una autorización de residencia y

13 La moratoria a la libertad de circulación laboral para Polonia expiró el 1 de mayo de 2006, para Bulgaria y Rumanía lo hizo el 1 de enero de 2009. No obstante en el año 2011 el Gobierno español decidió restituir la moratoria para los ciudadanos rumanos hasta el 31 de diciembre de 2013. Esta decisión fue motivada por la situación nacional de empleo, la importante colonia rumana presente en España y el derecho reconocido por la normativa comunitaria a fijar un máximo de 6 años como período de moratoria desde que el nuevo Estado pasa a formar parte de la UE.

14 BOE de 28 de febrero de 2007. El texto ha sufrido diversas reformas por normas posteriores.

15 Resolución de 26 de diciembre de 2007, de la Secretaría de Estado de Inmigración y Emigración, por la que se dispone la publicación del Acuerdo de Consejo de Ministros, de 21 de diciembre de 2007, por el que se regula el contingente de trabajadores extranjeros de régimen no comunitario en España para el año 2008 (BOE de 12 de enero de 2008).

16 BOE de 12 de diciembre de 2009. Al respecto, Monereo y Triguero (2010) indican que con la nueva reforma de la ley de extranjería e inmigración se produce un avance significativo para la regulación del estatuto jurídico de derechos de los nacionales de terceros Estados en nuestro país en la dirección de adecuar su regulación legal conforme a los esquemas constitucionalmente establecidos que, a su vez, se encuentran en clara consonancia con lo establecido a nivel internacional en los grandes Tratados, Acuerdos, Pactos o Convenios de los que España es parte. Derechos que, de modo inequívoco, son intrínsecos a la persona y a su dignidad, lo que hace que tengan el carácter de derechos fundamentales de todo hombre en cualquier Estado, siendo éstos expresión máxima de los derechos humanos. No obstante, este avance social legalmente recogido es de más difícil concreción en el plano práctico. 
trabajo específica que se regula mediante un nuevo Reglamento de Extranjería. Este procedimiento proporciona a las explotaciones frutícolas la mano de obra necesaria para las actividades de temporada, a través de la autorización de residencia temporal y trabajo por cuenta ajena de duración determinada ${ }^{17}$ que permite la realización de actividades o servicios de temporada o campaña y puede limitarse a una actividad y ámbito geográfico concreto. Su duración coincide con la del contrato de trabajo y no puede exceder de nueve meses, dentro de un periodo de doce meses consecutivos.

La obtención de esta autorización se inicia con la presentación de las ofertas de empleo por parte del empresario, o la organización empresarial a la que pertenezca, ante la Comisión Provincial creada en las Delegaciones y Subdelegaciones del Gobierno, una vez verificada que la SNE permite acudir a esta vía de contratación. Para ello, el empleador debe tramitar previamente la demanda de trabajadores ante el Servicio Público de Empleo para certificar que no se encuentran candidatos españoles, comunitarios o nacionales de terceros Estados residentes en España y con autorización de trabajo dispuestos a cubrir las vacantes. Tras este trámite, la oferta podrá gestionarse a través de la GECCO de forma genérica o nominativa. Esta última va dirigida a empleados "repetidores", los cuales ya han sido contratados previamente por el empresario frutícola en campañas anteriores. En todos los casos, las ofertas deben presentarse tres meses antes de la fecha de inicio del trabajo temporal en cualquier sector de actividad.

Se trata de un proceso con una tramitación compleja y que no resulta barato, cuestión que es puesta de manifiesto por los empresarios entrevistados. En primer lugar, el empleador debe ir al país de origen a realizar la selección de trabajadores a los que va dirigida la oferta genérica, labor que realiza conjuntamente con la Administración española y la del país en cuestión, estando en ocasiones también presentes los sindicatos. No obstante, es frecuente que este trámite de selección y formalización del precontrato de trabajo lo realice la organización empresarial de la que el agricultor es socio, delegando estas funciones en sus representantes y pagando una cuota por la prestación de estos servicios ${ }^{18}$. Generalmente los grandes empresarios, que contra-

\footnotetext{
Véase en Gordo y Márquez (2014) los requisitos a cumplir para obtener una respuesta favorable a la petición. Achón (2013) indica que, de este modo, la normativa que regula el proceso de contratación en origen de temporeros agrícolas otorga la delegación de facultades públicas a las organizaciones empresariales en cuanto les concede representación legal empresarial para reclutar en nombre de aquellos empresarios agrícolas, incapaces de llevar a cabo por sí mismos la contratación de mano de obra en origen. El reclutamiento en masa de trabajadores extranjeros se efectúa merced tal representación, dispositivo que, por otro lado, sirve a la gestión de su suministro y al control de su movilidad. En efecto, el Estado ha reservado la administración de los contingentes de temporeros reclutados para efectuar labores de recolección a las organizaciones empresariales más importantes, transformándolas en ejecutores de la política de control de flujos migratorios. Dicho procedimiento ha provocado el empoderamiento de las organizaciones señaladas por ley para la realización del proceso de reclutamiento e importación de temporeros agrícolas. Estas son las organizaciones empresariales más representativas de cada sector para cada comunidad autónoma. Merced el otorgamiento de este estatuto de privilegio los sindicatos agrícolas actúan como agentes implementadores de la política de control de flujos. Varios dispositivos permiten esta transformación, la delegación de representatividad legal empresarial -para contratar por un grupo de empresarios- y de función pública -para velar por el regreso del trabajador extranjero a su país de origen, su concentración en alojamientos para ellos destinados y el buen desempeño del trabajo que realizan durante el período que dura su permiso de trabajo y residencia en España. En contraposición a la tesis de Achón que atribuye el empoderamiento de las organizaciones empresariales agrícolas merced la legislación de extranjería, Sánchez-Rodas (2010) en su estudio de la naturaleza contractual del precontrato de trabajo indica que el precontrato a favor de terceros (las organizaciones empresariales pactan con los trabajadores en origen la celebración de un contrato con los empresarios agrícolas) no es un verdadero precontrato de trabajo. Argumenta que un sector doctrinal
} 
tan un número elevado de temporeros, son los que se desplazan personalmente para participar en el proceso de selección y acuerdo para futuro contrato laboral.

En segundo lugar, se tramitan los visados para que el trabajador pueda salir del país y entrar en España. Tambíen es necesario organizar el viaje de ida y vuelta, en el que las empresas asumen parte de los gastos de transporte, y debe garantizarse un alojamiento digno a los temporeros. Los empresarios frutícolas y sindicatos agrarios entrevistados han valorado positivamente la posibilidad de contratar mediante la GECCO al mismo trabajador durante diferentes campañas, a través de ofertas nominativas, puesto que con ello se recupera la formación y experiencia de este capital humano, a la vez que es una forma de reducir los costes asociados al proceso de selección en el país de origen.

Por su parte el trabajador debe cumplir con el "compromiso de retorno" a su país de origen tras finalizar la relación laboral. Para acreditar este regreso tiene que presentarse en la Misión diplomática o en la Oficina consular que le expidió el visado, en el plazo de un mes desde el término de su autorización en España. La acreditación del regreso, además del cumplimiento del resto de obligaciones laborales, le facultará para cubrir otras posibles ofertas de empleo que se generen en la misma actividad, esta vez mediante una oferta nominativa. Por contra, el incumplimiento de esta obligación podrá ser causa de denegación de ulteriores solicitudes de autorizaciones para trabajar, durante los tres años siguientes al término de la autorización concedida.

La mayor parte de las solicitudes aprobadas mediante la GECCO son cubiertas por temporeros que llegan para las cosechas vinculadas a la frutícola de vanguardia que se producen en la provincia de Huelva, en particular para la recolección de las fresas, arándanos, moras, frambuesas y cítricos, y en menor medida también para la plantación de las berries y las labores de manipulado agroindustrial. Los agricultores onubenses acapararon 44.196 plazas de las 70.694 concedidas en el año 2007 (MTIN, 2008) y 31.699 de las 53.101 de 2008 (MITIN, 2009). La agricultura frutícola de la provincia de Lérida es la segunda en importancia. En el año 2008 llegaron 4.843 braceros a través de este procedimiento a los fruticultura leridana (MTIN, 2009).

\section{La recesión y su anhelada recuperación (2009-2016)}

A partir del año 2008, los cupos aprobados en el marco de la GECCO han sufrido importantes recortes debido a la elevada tasa de desempleo generada por una coyuntura económica recesiva. La destrucción de ocupación en el mercado de trabajo y la articulación de la normativa de extranjería española en torno a la protección del trabajador nacional, comunitario y otros extranjeros residentes en España, hace que estos trabajadores tengan prioridad para acceder al mercado laboral. Ello ha dado lugar a que la mayor parte de los cupos autorizados sean para temporeros "repetidores".

considera que se trata de unos simples tratos preliminares porque la oferta emitida por el empresario (frutícola en nuestro caso) no va dirigida a un trabajador concreto y como consecuencia de ello falta la aceptación de la misma, esto es, la aceptación de ponerse a disposición del empleador, lo cual da lugar al incumplimiento del requisito del consentimiento. En este caso, el contrato de trabajo nunca podrá llegar a existir sin la conformidad de un tercero que no ha sido parte en el precontrato y que por ello no se ha obligado a obligarse laboralmente. Con lo cual, las partes nunca podrán exigirse recíprocamente la celebración de ningún contrato de trabajo. 
No obstante, los empresarios frutícolas y sindicatos indican que durante los primeros años de la crisis los trabajadores desempleados, residentes en el país, se mostraban reticentes a participar de manera significativa en las campañas de recolección, aduciendo los bajos salarios, la dureza del trabajo o la sobreeducación para realizar trabajos no cualificados.

Sin embargo, a partir de 2011 y ante la falta de expectativas en otros sectores se produce un retorno significativo hacia las actividades temporales del sector frutícola por parte de los desempleados españoles, y de los extranjeros residentes en el país. En este contexto de mayor disponibilidad laboral nacional, en la provincia de Huelva desde la campaña 2011/2012 se aprueba un cupo de reserva de 2.000 plazas, formado por mujeres marroquíes repetidoras de más de dos años y que han cumplido el compromiso de retorno a su país de orgien, lo que las convierte en mano de obra fidelizada y especializada para el sector, al que sólo se acudiría de manera puntual para garantizar la recogida de las fresas y berries. Por su parte, la Subdelegación del Gobierno de Lérida en el año 2013 anuncia que limita a siete meses el periodo de contratación de temporeros extranjeros en origen para trabajar en la campaña de fruta.

En este contexto de plena recesión se aprueba el nuevo Reglamento de Extranjería, Real Decreto 557/2011, de 20 de abril ${ }^{19}$, que sustituye el Real Decreto 2393/2004. Mantiene las actividades de temporada como un régimen especial al que se vincula la "autorización de residencia temporal y trabajo por cuenta ajena de duración determinada ${ }^{20 "}$. Regula también la denominada GECCO, que se limita a

19 El reglamento incide en los aspectos para acometer el cambio de ciclo migratorio, a tenor de la nueva realidad socioeconómica, mediante el fomento de la integración y la igualdad de derechos y deberes; la consolidación de un modelo migratorio basado en la regularidad; el fortalecimiento de la colaboración con las Administraciones locales y autonómicas; la inclusión de mecanismos para fomentar y garantizar la movilidad y la simplificación de los trámites burocráticos, la armonización jurídica respecto de determinadas Directivas europeas que configuran un marco normativo europeo común en materia de inmigración en el que España participa plenamente y el desarrollo de los diversos procedimientos de gestión y la adecuada articulación del fenómeno migratorio en nuestro país (BOE de 30 de abril de 2011).

20 La autorización de residencia temporal y trabajo por cuenta ajena de duración determinada permite, entre otras, el desarrollo de actividades de temporada o campaña, con requisitos similares al procedimiento anterior. La duración de la autorización coincidirá con la duración del contrato/s de trabajo, con el límite de nueve meses, dentro de un periodo de doce consecutivos. Se mantiene el requisito que el trabajador extranjero se comprometa a retornar al país de origen, una vez concluida la relación laboral, so pena de denegación de ulteriores solicitudes para trabajar en los tres años siguientes. Se mantiene el requisito de que el empleador ponga a disposición un alojamiento adecuado, que organice los viajes de llegada a España y regreso al país de origen, asumiendo como mínimo el coste del primero de ellos y los gastos de traslado de ida/vuelta entre el puesto de entrada a España y el lugar de alojamiento. El procedimiento de las actividades de temporada establece que las ofertas de empleo serán puestas a disposición del SPE estatal o comunitario para publicitarlas durante veinticinco días, a los efectos de que el trabajador residente en España pueda concurrir a su cobertura. Tras dicho plazo, las solicitudes vacantes se presentan por las empresas o por las organizaciones empresariales, que tienen atribuida la representación legal empresarial, con una antelación mínima de tres meses al inicio de la actividad laboral. En caso favorable se notificará al empleador la autorización de residencia temporal y trabajo por cuenta ajena de duración determinada, cuya eficacia queda supeditada a la expedición del visado y la efectiva entrada del trabajador extranjero en territorio nacional. Cuando la autoridad competente disponga de los contratos firmados por los empresarios aprobará la autorización e indicará la ocupación, ámbito territorial y duración autorizados. Se remiten los contratos al empresario para que los firme el trabajador en el país de origen, ante la oficina consular competente para la expedición del visado. La vigencia de la autorización se inicia en la fecha en que se efectúa la entrada del trabajador en España. Si en el plazo de un mes desde su entrada no existe constancia de que el trabajador ha sido dado de alta en el Régimen de la Seg. Soc., el órgano competente requerirá al empleador las razones de ello, advirtiendo que en caso no justificado podrá resolver la extinción de la autorización y podrán denegarse ulteriores solicitudes al considerar que no se garantiza la actividad continuada de los trabajadores. 
los supuestos en los que se pretende la contratación de 10 o más trabajadores para una misma actividad. No obstante, la Dirección General de Migraciones podrá autorizar, excepcionalmente, la gestión de ofertas que contengan un número mínimo de 5 puestos de trabajo.

Esta situación de descenso en la autorización de los cupos, con el objetivo de dar preferencia a los trabajadores en situación de desempleo que se encuentran en España, y que sean ellos los que realicen las tareas de recolección de las campañas, lleva a que en el año 2015 el Ministerio de Empleo tome la decisión de que no haya contingente de mano de obra extranjera.

La incorporación de los trabajadores españoles y los extranjeros residentes en el país a las campañas de recolección se produce en el contexto de reforma del mercado laboral. La Ley 3/2012, de 6 de julio, de medidas urgentes para la reforma del mercado laboral (LRML) ${ }^{21}$ regula en el capítulo primero que las Empresas de Trabajo Temporal (ETT) podrán actuar como agencias de colocación, para lo cual deberán obtener autorización previa. La reforma laboral apostó por intensificar la colaboración público-privada de los servicios públicos de empleo. Según el preámbulo de la Ley, las ETT se han revelado como un potente agente dinamizador del mercado de trabajo. En la mayoría de los países de la UE, tales empresas operan como agencias de colocación y desde las instituciones comunitarias se viene subrayando que las mismas contribuyen a la creación de puestos de trabajo y a la participación e inserción de trabajadores en el mercado de trabajo ${ }^{22}$. Según ciertos autores (Baylos, 2013 o Cabasés y Pardell, 2014) estamos asistiendo a la articulación jurídica en términos de mercantilización y privatización del empleo y la consideración del desempleo como un hecho privado sometido a la lógica de la oferta y la demanda.

Este cambio normativo lleva a que las ETT operen en las campañas agrarias de recolección de fruta. Castellón fue uno de los primeros enclaves frutícolas que vio como los temporeros de la campaña de cítricos llegaban contratados a través de las ETT ${ }^{23}$. En la campaña de cítricos de 2012 las empresas contrataron de forma directa a 8.500 temporeros para el manipulado y envasado en las centrales ( $90 \%$ fijos discontinuos) y mediante ETT unos 1.300. Para la recolección las empresas contrataron alrededor de 12.000 temporeros (fijos discontinuos) y a través de ETT unos 2.500. La alternativa que supone el recurso a las ETT se justifica por el hecho de suponer un modelo ágil para hacer frente a las necesidades de los empresarios frutícolas que demandan mano de obra puntual en función de las necesidades diarias o semanales de la recolección.

Destacar que los sindicatos entrevistados apuntan que la cesión de trabajadores de las ETT ha crecido en cada campaña a expensas de los contratados fijos disconti-

\footnotetext{
BOE de 7 de julio de 2012 .

22 En noviembre de 2006, la Comisión Europea presentó el Libro Verde "Modernizar el Derecho Laboral para afrontar los retos del siglo XXI" en el que se realiza un diagnóstico de situación de la legislación laboral y su evolución desde principios de los noventa, caracterizado por la creciente segmentación de los mercados de trabajo, la mayor utilización de formas contractuales distintas de las relaciones típicas por tiempo indefinido o tiempo completo (por ejemplo contratos de duración determinada, contrato a tiempo parcial, contratos para cesión de trabajadores por ETT) y el aumento del trabajo autónomo (CES, 2007).

23 Cabe destacar que en la Región de Murcia la evolución de los contratos de puesta a disposición gestionados por las ETT ha mantenido un crecimiento sostenido desde 1994, año de su legalización, y se ha convertido en una práctica habitual, no sólo en los sectores con mayor dependencia de la estacionalidad como la agricultura. Sin embargo, la cesión de trabajadores de las ETT en esta región se focaliza principalmente hacia empresas de pequeño-mediano tamaño y para actividades estacionales comprendidas dentro del sector de la agricultura hortofrutícola (Andreo et al., 2005).
} 
nuos por parte de los empresarios. Éstas ofrecen un modelo de gestión en las relaciones laborales diferente al que se produce mediante el contrato directo entre temporero-empresario frutícola, que se concreta en la regulación de los contratos de puesta a disposición. Los trabajadores son contratados por las ETT, que pagan su salario y formalizan las altas/bajas en la Seguridad Social. De este modo, mediante el contrato de puesta a disposición, se produce un acuerdo entre la ETT y el empresario frutícola mediante el cual la primera cede temporalmente sus trabajadores al segundo. Ello ha dado lugar a situaciones abusivas, denunciadas por los principales sindicatos, que señalan a varías empresas de trabajo temporal por realizar fraude salarial y de cotización a la Seguridad Social y aplicar jornadas de trabajo maratonianas.

En Huelva y Lérida, la contratación de temporeros mediante ETT tampoco está exenta de críticas por parte de los sindicatos agrarios. UGT censuró en la campaña de la fresa de 2013 la contratación de temporeros rumanos a través de ETT procedentes de Rumania y Francia mediante prácticas ilegales y fuera del convenio del campo. El sindicato conminó a los empresarios onubenses a priorizar la mano de obra local y respetar el convenio colectivo en relación a las condiciones salariales y de alojamiento. En Lérida los principales sindicatos agrarios denuncian que en la campaña de 2015 y la de 2016 los salarios que perciben los temporeros contratados a través de algunas ETT están por debajo de lo pactado en el convenio (3 ó 4 euros la hora, frente a los 6,06 que marca el convenio). Como señalan Cabasés y Pardell (2014) al abrirse la puerta de la colaboración público-privada muchas son las agencias de colocación multinacionales que esperan hacer negocio en España.

En estos enclaves frutícolas se observa un elevado riesgo de desregulación de las condiciones laborales de las campañas de recolección. Para atajar estas situaciones de fraude laboral la Inspección de Trabajo de cada provincia realiza visitas a las fincas para comprobar que los temporeros trabajan en condiciones ajustadas a los convenios. Sin embargo, sus responsables manifiestan que no siempre es fácil comprobar estas irregularidades. Los sindicatos consideran necesario, para acabar con esta precariedad laboral, que los convenios obliguen a las empresas a garantizar un determinado volumen de contratación directa (alrededor del 80\%) y la contratación a través de las empresas temporales se realice cuando existan causas justificadas para ello. De este modo, se pretende evitar situaciones como la que se observa en el "modelo murciano" donde la importancia de los contratos de puesta a disposición constituye un caso paradigmático en la contratación de trabajadores temporales en el sector agrario a través de ETT (Andreo, 2007).

El 26 de febrero de 2014 se aprobó la Directiva 2014/36/UE sobre las condiciones de entrada y estancia de nacionales de terceros países para fines de empleo como trabajadores temporeros ${ }^{24}$ con el objetivo de "contribuir a una gestión efectiva de los flujos migratorios en la categoría específica de la migración temporal de carácter estacional y a garantizar condiciones dignas de trabajo y de vida para los trabajadores temporeros, mediante el establecimiento de normas de admisión y estancia justas y transparentes y la definición de los derechos de dichos trabajadores, sin dejar por ello de ofrecer al mismo tiempo incentivos y salvaguardias para evitar que la estancia temporal se prolongue más de lo permitido o se convierta en permanente". La transposición de esta Directiva al ordenamiento jurídico interno de cada Estado miembro debería realizarse no más tarde del 30 de septiembre de 2016. En cualquier caso, los

DOUE L 94/375, de 28 de marzo de 2014. 
Estados miembros mantienen su derecho a determinar los volúmenes de admisión que estimen oportuno.

\section{Conclusiones}

Las condiciones laborales que ofrecen las campañas agrarias de recolección, con un fuerte carácter cíclico, bajos salarios, dureza del trabajo y baja consideración social, propician los éxodos laborales de los temporeros hacia otros sectores. En este contexto, la legislación se ha adaptado progresivamente a las necesidades de las explotaciones agrarias y a su evolución. Es por ello, que en las últimas décadas las actividades agrarias, como la frutícola que requieren de mano de obra temporal de manera intensiva, han experimentado diferentes estrategias de reclutamiento de esta mano de obra que han llevado a un proceso de sustitución entre jornaleros nacionales y extranjeros.

Este relevo entre la contratación de temporeros de nacionalidad española y de procedencia extranjera está muy condicionado a la coyuntura económica del momento. Las etapas de crisis, como la que tuvo lugar hasta mediados de los ochenta y a partir del año 2009, favorecen el efecto llamada de los trabajadores españoles hacia las actividades frutícolas y de temporada. Por el contrario, las etapas de crecimiento, asociadas a la entrada a la UE y posteriormente a la UEM, han ejercido el efecto llamada de los temporeros extranjeros.

Con el cambio de siglo, la GECCO de trabajadores extranjeros en origen ha facilitado a los empresarios frutícolas de los enclaves estudiados la mano de obra temporal necesaria para las actividades de campaña.

Sin embargo, a partir del año 2008 la GECCO pasa a ser objeto de importantes recortes motivados por los efectos económicos de la crisis y por las elevadas tasas de desempleo que se van generando. La destrucción de ocupación y los cambios normativos en materia de extranjería orientados hacia una mayor protección del trabajador nacional, comunitario y extranjero residente en España, facilita que estos tengan preferencia respecto los procedentes del exterior.

A pesar de que en los primeros años de la crisis existía una significativa reticencia, por parte de los trabajadores desempleados residentes, en participar significativamente en las campañas frutícolas, es a partir del año 2011 cuando se produce un cambio de tendencia en el que estos trabajadores ponen de manifiesto una mayor disponibilidad laboral hacia dichas campañas.

La investigación evidencia que en los últimos años se ha producido un giro en las preferencias contractuales mostradas por estos empresarios agrícolas en cuanto al reclutamiento de jornaleros a través de contratos de puesta a disposición de las Empresas de Trabajo Temporales, no exento de críticas por la desregulación de las condiciones laborales que conlleva. El cambio normativo potencia la participación de estas empresas en las campañas agrícolas de recolección a la vez que el empresariado manifiesta también su preferencia a este recurso. El modelo de las ETT se adapta al sistema de temporalidad que caracteriza el trabajo de los temporeros del sector frutícola y ofrece una clara flexibilidad al empleador en relación con el trabajador. Son los sindicatos los que censuran las prácticas de prestación de trabajadores por los efectos nocivos sobre las condiciones de trabajo y el incumplimiento del 
convenio colectivo del campo. El carácter temporal y discontinuo de las tareas de recolección agrícola y los bajos salarios hacen del trabajo en el campo una actividad atractiva para la contratación de puesta a disposición que protagonizan y gestionan estas empresas. Andreo et al. (2005) en su estudio sobre la intermediación laboral a través de las ETT en la Región de Murcia afirman que la noción de flexibilidad suscita posiciones diferentes y no es materia de consenso. Destacan que la flexibilidad es un ingrediente más de un conjunto de factores que incluyen competitividad y tecnología y que permite una mayor reducción de la tasa de desempleo. No obstante, reconocen que también se interpreta como sinónimo de precarización social.

En definitiva, podemos concluir que la contratación de temporeros es un rasgo característico de la agricultura frutícola que se basa en la existencia de colectivos dispuestos a ser contratados como mano de obra temporal y la contención de costes salariales como estrategia para alcanzar mejoras competitivas. Las empresas frutícolas defienden este mecanismo aduciendo los bajos precios de venta de sus productos agrarios que se forman en un mercado estructurado de arriba hacia abajo. En la misma línea, Gadea et al. (2015) afirman que la evolución de los mercados laborales agrícolas en España ha venido marcada por la búsqueda de estrategias de fijación y de movilización continua de trabajadores, con el objetivo de cubrir las necesidades de trabajo barato y disponible en una agroindustria que ha tratado de contener los costes laborales para producir en condiciones de competitividad.

\section{Bibliografia}

Achón, O. (2011): Importando miseria. La alternativa a la provisión de mano de obra agrícola. Madrid: Catarata.

Achón, O. (2013): "El empoderamiento de las organizaciones empresariales agrícolas merced la legislación de extranjería y su transformación en agentes ejecutores de la política de control de flujos. El caso de Unió de Pagesos". Revista de Ciencias Sociales, núm. 30, pp. 46-73.

Andreo, J.C.; Guerrero, M.J; Arcos, B. y Gálvez, D. (2005): “Intermediación en el mercado laboral de mano de obra inmigrante extranjera en la Región de Murcia: el caso de las empresas de trabajo temporal". Papeles de Geografía, núm. 41-42, pp. 51-59.

Andreo, J.C. (2007): Inmigración extranjera y empresa de trabajo temporal en la región de Murcia, Madrid, Doble, J. Colección Ciencias Sociales.

Aragón, R. y Chozas, J. (1993): La regularización de inmigrantes durante 1991-1992. Madrid: Ministerio de Trabajo y Seguridad Social.

Baylos, A. (2013): "La desconstitucionalización del trabajo en la reforma laboral del 2012". Revista de Derecho Social, núm. 61, pp. 19-42.

Cabasés, M. A. y Pardell, A. (2014): Una visión crítica del Plan de Implantación de la Garantía Juvenil en España. Albacete: Editorial Bomarzo.

CES (2007): Memoria sobre la situación socioeconómica y laboral de España 2006. Consejo Económico y Social.

Gadea, E.; Castro, C.; Pedreño, A. y Morales, N. (2015): “Jornaleros inmigrantes en la agricultura murciana: reflexiones sobre crisis, inmigración y empleo agrícola". Migraciones, núm. 33, pp. 149-169.

Gordo, M. (2011):'Los contratos en origen de temporada a las "marroquinas": estrategia em- 
presarial para sustituir a las trabajadoras del Este de Europa tras la incorporación de estos países a la UE". Actas del XI Congreso de la Asociación Andaluza de Ciencia Regional de Andalucía.

Gordo, M. y Márquez, J. A. (Dirs.) (2014): Estudio cuantitativo-cualitativo sobre transferencia del modelo de sistemas de movilidad de flujos migratorios en Huelva a otras provincias andaluzas. Sevilla: Fundación AFIES.

Majoral, R. y Sánchez-Aguilera, D. (2002): “Las mujeres en el sector agrario y el medio rural español. Libro Blanco de la Agricultura y el Desarrollo Rural”.

Ministerio del Interior (1997, 2000, 2008 y 2009): Anuario de Extranjería, diversos años. Madrid: Ministerio del Interior.

Ministerio de Agricultura, Alimentación y Medio Ambiente (2015): Informe Anual: El comercio exterior agroalimentario y pesquero 2014. MAAMA.

Monereo, JL. y Triguero, LA. (2010): "El modelo de protección legal del trabajador extranjero tras la reforma realizada por la Ley Orgánica 2/2009, de 11 de septiembre. Revista Doctrina Aranzadi Social, núm. 20/2010.

Sánchez-Rodas, C. (2010): El Precontrato de Trabajo. Régimen Jurídico. Aranzadi-Thomsom Reuters.

Segura, P.; Pedreño, A. y de Juana, S. (2002): “Configurando la Región Murciana para las frutas y hortalizas: racionalización productiva, agricultura salarial y nueva estructura social del trabajo jornalero". Areas. Revista Internacional de Ciencias Sociales, núm. 22, pp. 71-93.

Tabares, E. (1990): “Jornaleros y temporeros”. La acción social. Cuadernos de formación, núm. 14. Caritas.

Vilar, J.B.; Bel, C.; Gómez, J. y Egea, P.M. (1999): Las emigraciones murcianas contemporáneas. Murcia: Universidad de Murcia. 